\title{
RESPONS PERTUMBUHAN DAN PRODUKSI DUA VARIETAS UBI JALAR TERHADAP PEMBERIAN BERBAGAI SUMBER KALIUM
}

\author{
Wendy V K Sembiring \\ Program Studi Agroteknologi \\ Fakultas Pertanian, Universitas Sumatera Utara, Medan 20155, Indonesia \\ wendysembiring@gmail.com
}

\begin{abstract}
The research was conducted at Tanjung Anom Subdistrict of Pancur Batu, Deli Serdang District of Medan, North Sumatera with an altitude of \pm 25 meters above sea level from April until August 2017, using group randomized design with two factors, i.e : varieties (Beta 1 and Local Perbaungan) and sources of potassium (control, $\mathrm{KCl}$, biochar, empty palm fruit bunch). The result showed that the treatment of two varieties had significant effect on tuber length parameters per sample, biomass weight per sample, tuber weight, and plant biomass weight, that the highest yield was obtained in Beta 1 treatment. The sources of potassium significantly affect all parameters of the study the interaction of the treatment of varieties and the provision of various types of potassium sources significantly affected all parameters, where the number of tubers and tuber weight per sample of treatment was highest in the treatment of Beta 1 varieties with $\mathrm{KCl}$.
\end{abstract}

\begin{abstract}
Abstrak
Penelitian dilaksanakan di lahan masyarakat Kelurahan Tanjung Anom Kecamatan Pancur Batu Kabupaten Deli Serdang Medan Sumatera Utara dengan ketinggian tempat \pm 25 meter di atas permukaan laut mulai bulan April sampai Agustus 2017, dengan dua faktor perlakuan, yaitu : Varietas (Beta 1 dan Lokal Perbaungan) dan Berbagai Sumber Kalium ( kontrol, KCl, biochar, dan TKKS). Hasil dari penelitian ini menunjukkan bahwa perlakuan dua varietas berpengaruh nyata pada parameter panjang umbi per sampel, bobot biomassa per sampel,rataan bobot umbi, dan bobot biomassa tanaman, dimana hasil tertinggi diperoleh pada perlakuan varietas Beta 1. Pemberian sumber kalium berpengaruh nyata terhadap semua parameter penelitian, interaksi perlakuan varietas dan pemberian berbagai jenis sumber kalium berpengaruh nyata pada semua parameter, dimana jumlah umbi dan bobot umbi per sampel tertinggi terdapat pada perlakuan varietas Beta 1 dengan $\mathrm{KCl}$.
\end{abstract}

Kata Kunci : Ubi Jalar, Varietas, Sumber Kalium

\section{Pendahuluan}

Tanaman ubi jalar (Ipomoea batatas L.) merupakan komoditas yang bernilai ekonomi tinggi dan banyak memberikan manfaat, selain mempunyai kandungan karbohidrat tinggi juga mengandung berbagai nutrisi yang berguna bagi kesehatan tubuh sehingga dimungkinkan untuk dijadikan sebagai sumber utama subtitusi beras atau sebagai pangan alternatif. Keuntungan lainnya adalah dapat tumbuh di berbagai kondisi tanah, sehingga sangat strategis apabila dikembangkan di berbagai daerah marginal sebagai pendukung diversifikasi pangan (Dinas Pertanian Tanaman Pangan, 2012). 
Varietas unggul baru merupakan komponen teknologi produksi yang sangat strategis dalam upaya meningkatkan produksi ubi jalar karena berkaitan dengan potensi hasil yang tinggi. Varietas unggul baru yang mempunyai karakter sesuai dengan kebutuhan dan preferensi pengguna juga relatif mudah diterima petani, dan kompatibel dengan komponen teknologi budidaya lain. Hingga tahun 2009, Badan Litbang Pertanian telah melepas masing-masing 10 varietas unggul ubi kayu dan 19 ubi jalar, masing-masing dengan sifat keunggulan (Saleh, 2011).

Ubi jalar varietas Beta 1 yaitu berasal dari persilangan bebas induk betina MSU 01015. Umur panen tanaman 4-4,5 bulan. Hasil produksi 25-35 ton/ha. Adapun keunggulan dari ubi jalar varietas Beta 1 adalah kadar betakaroten $12.032 \mu \mathrm{g} / 100 \mathrm{~g}$ bahan, agak tahan kudis dan boleng (Balai Penelitian Tanaman Kacang dan Umbi-umbian, 2011).

Ubi jalar varietas lokal Perbaungan memiliki umur panen tanaman 4-4,5 bulan, hasil produksi 15-20 ton/ha. Adapun keunggulan dari ubi jalar varietas lokal Perbaungan adalah kadar betakaroten $4.629 \mu \mathrm{g} / 100 \mathrm{~g}$ bahan, agak tahan kudis dan boleng (Balai Penelitian Tanaman Kacang dan Umbi-umbian, 2012).

Usaha yang dapat dilakukan dalam meningkatkan produksi ubi jalar adalah dengan melakukan pemupukan baik pupuk organik maupun anorganik. Salah satu pupuk anorganik yang dibutuhkan tanaman ubi jalar yang dapat memperbaiki pertumbuhan dan perkembangan terutama umbi adalah kalium. Kalium adalah suatu satu unsur hara esensial yang di butuhkan oleh tanaman dalam jumlah besar. Kalium di serap tanaman dalam bentuk ion $\mathrm{K}+$ di dalam tanah. Ion ini bersifat dinamis, sehingga mudah tercuci tanah berpasir dan tanah dengan $\mathrm{pH}$ rendah. Peran kalium dalam tanaman, yakni membantu proses fotosintesis, untuk membentuk senyawa organik baru yang akan ditranslokasikan ke organ tempat penyimpanan dalam hal ini umbi dan sekaligus memperbaiki kualitas umbi tanaman ubi jalar. $\mathrm{KCl}$ adalah pupuk buatan yang mengandung Kalium (52\% K20) di mana untuk memenuhi kebutuhan unsur hara dan perbaikan tanah (Sianturi dan Ernita, 2014).

Salah satu pupuk anorganik yang dibutuhkan oleh tanaman ubi jalar yang dapat memperbaiki pertumbuhan dan perkembangan terutama umbi adalah kalium. Kalium adalah salah satu unsur hara essensial yang dibutuhkan oleh tanaman dalam jumlah besar. Peran kalium dalam tanaman, yakni membantu proses fotosintesis untuk membentuk senyawa organik baru yang akan ditranslokasikan ke organ tempat penyimpanan. Dalam hal ini umbi sekaligus memperbaiki kualitas umbi tanaman ubi jalar (Sianturi dan Ernita, 2014).

Sekam dapat diproses menjadi biochar (emas hitam untuk pertanian) yang digunakan sebagai amelioran utama untuk meningkatkan kandungan bahan organik, menaikkan $\mathrm{pH}$ dan produksi berbagai tanaman. Biochar merupakan senyawa organik berkarbon tinggi (40 $60 \%$ ) hasil proses pirolisis (karbonisasi) yang resisten terhadap pelapukan sehingga mampu berfungsi sebagai amelioran organik yang efektif untuk memperbaiki kesuburan tanah dan mampu bertahan hingga ratusan tahun di dalam tanah (Sudjana, 2014). 
Tandan kosong merupakan limbah kelapa sawit yang kaya akan unsur kalium. Kompos tandan kosong kelapa sawit memiliki kandungan unsur hara yang cukup yaitu $\mathrm{C}=35 \%, \mathrm{~N}$ $=2,34 \%, \mathrm{P}=0,31 \%, \mathrm{~K}=5,53 \%, \mathrm{Ca}=1,46 \%, \mathrm{Mg}=0,96 \%$, dan air $=96 \%$ (Pusat Penelitian Kelapa Sawit, 2006).

\section{Bahan dan Metode}

Penelitian dilaksanakan di lahan masyarakat Kelurahan Tanjung Anom Kecamatan Pancur Batu Kabupaten Deli Serdang Medan Sumatera Utara dengan ketinggian tempat \pm 25 meter di atas permukaan laut mulai bulan April 2017 sampai Agustus 2017

Bahan yang digunakan pada penelitian ini adalah benih jagung varietas Bonanza, Secada Bahan yang digunakan ialah bibit stek pucuk ubi jalar varietas Beta 1, dan varietas lokal Perbaungan, pupuk KCl, pupuk Urea dan TSP, biochar sekam padi dan kompos TKKS, air dan bahan-bahan lain yang mendukung penelitian ini. Alat yang digunakan yaitu cangkul, pisau/cutter, pacak sampel, meteran, timbangan analitik, gembor, serta alat pendukung lainnya.

Penelitian menggunakan rancangan acak kelompok (RAK) dengan 2 faktor. Jika dari hasil analisis sidik ragam menunjukkan pengaruh yang nyata, maka dilanjutkan dengan Uji Beda Rataan berdasarkan Duncan Multiple Range Test (DMRT) pada taraf 5\% (Steel and Torrie, 1989).

Parameter yang di amati antara lain : Pertambahan Panjang Tanaman $(\mathrm{cm})$, Jumlah Umbi Per Sampel (umbi), Panjang Umbi Per Sampel (cm), Bobot Umbi Per Sampel (g), Rataan bobot umbi , Bobot Biomassa Tanaman Per Sampel (g) dan Indeks panen.

\section{Hasil dan Pembahasan}

\section{Hasil}

\section{Pertambahan Panjang Tanaman (cm)}

Hasil uji beda rataan pengaruh pemberian berbagai sumber kalium terhadap pertambahan panjang tanaman $(\mathrm{cm})$ disajikan pada Tabel 1.

Dari hasil uji rataan pada taraf 5\% yang terdapat pada Tabel 1 memperlihatkan bahwa penggunaan dua varietas ubi jalar dan pemberian berbagai sumber kalium serta interaksi kedua perlakuan tersebut berpengaruh nyata terhadap pertambahan panjangan ubi jalar, dimana pertambahan panjang tanaman tertinggi terdapat pada perlakuan varietas Beta 1 dengan sumber $\mathrm{KCl}(\mathrm{V} 1 \mathrm{~K} 1)$ pada setiap minggu pengamatan, sedangkan pertambahan panjang tanaman terendah 
Tabel 1. Pertambahan panjang tanaman $(\mathrm{cm})$ dua varietas ubi jalar terhadap pemberian berbagai sumber kalium 1 MST sampai 10 MST

\begin{tabular}{|c|c|c|c|c|c|c|}
\hline \multirow[b]{2}{*}{ MST } & \multirow[b]{2}{*}{$\begin{array}{l}\text { Varietas } \\
\text { (V) }\end{array}$} & \multicolumn{4}{|c|}{ Sumber Kalium $(\mathrm{K})$} & \multirow[b]{2}{*}{ Rataan } \\
\hline & & $\begin{array}{c}\mathrm{K}_{0} \\
\text { (Kontrol) }\end{array}$ & $\begin{array}{c}\mathrm{K}_{1} \\
(\mathrm{KCl} \\
1,5 \mathrm{~g} / \text { tanaman })\end{array}$ & $\begin{array}{c}\mathrm{K}_{2} \\
\text { (Biochar } \\
500 \mathrm{~g} / \text { tanaman) }\end{array}$ & $\begin{array}{c}\mathrm{K}_{3} \\
(\mathrm{TKKS} \\
600 \mathrm{~g} \\
/ \text { tanaman) } \\
\end{array}$ & \\
\hline \multirow[t]{3}{*}{1} & $\mathrm{~V}_{1}$ (Beta 1) & $3,43 \mathrm{f}$ & $13,60 \mathrm{a}$ & $8,62 \mathrm{~d}$ & $9,60 \mathrm{c}$ & 10,55 \\
\hline & $\mathrm{V}_{2}$ (Perbaungan) & $10,10 \mathrm{~b}$ & $6,37 \mathrm{e}$ & $9,00 \mathrm{c}$ & $7,33 \mathrm{e}$ & 8,22 \\
\hline & Rataan & 6,80 & 9,98 & 8,81 & 8,40 & \\
\hline \multirow[t]{3}{*}{2} & $\mathrm{~V}_{1}$ (Beta 1) & $3,85 \mathrm{~h}$ & $15,61 \mathrm{a}$ & $11,45 \mathrm{c}$ & $11,30 \mathrm{~d}$ & 10,55 \\
\hline & $\mathrm{V}_{2}$ (Perbaungan) & $12,58 \mathrm{~b}$ & $7,23 \mathrm{~g}$ & $11,04 \mathrm{e}$ & $9,34 \mathrm{f}$ & 10,05 \\
\hline & Rataan & 8,21 & 11,42 & 11,25 & 10,32 & \\
\hline \multirow[t]{3}{*}{3} & $\mathrm{~V}_{1}$ (Beta 1) & $4,63 \mathrm{~h}$ & $18,63 \mathrm{a}$ & $12,46 \mathrm{e}$ & $14,03 \mathrm{c}$ & 12,44 \\
\hline & $V_{2}$ (Perbaungan) & $14,74 \mathrm{~b}$ & $9,41 \mathrm{~g}$ & $13,14 \mathrm{~d}$ & $11,68 \mathrm{f}$ & 12,24 \\
\hline & Rataan & 9,69 & 14,02 & 12,80 & 9,69 & \\
\hline \multirow[t]{3}{*}{4} & $\mathrm{~V}_{1}$ (Beta 1) & $5,22 \mathrm{~g}$ & $21,75 \mathrm{a}$ & $14,93 \mathrm{~d}$ & $15,98 \mathrm{c}$ & 14,47 \\
\hline & $\mathrm{V}_{2}$ (Perbaungan) & $17,80 \mathrm{~b}$ & $10,54 \mathrm{f}$ & $15,08 \mathrm{~d}$ & $13,90 \mathrm{e}$ & 14,33 \\
\hline & Rataan & 11,51 & 16,15 & 15,00 & 14,94 & \\
\hline \multirow[t]{3}{*}{5} & $V_{1}($ Beta 1) & 21,73 & 34,75 a & $32,53 \mathrm{~b}$ & $23,48 \mathrm{~g}$ & 28,12 \\
\hline & $V_{2}$ (Perbaungan) & $31,27 \mathrm{c}$ & $29,48 \mathrm{~d}$ & $26,54 \mathrm{e}$ & $23,93 \mathrm{f}$ & 27,81 \\
\hline & Rataan & 26,50 & 32,11 & 29,54 & 23,70 & \\
\hline \multirow[t]{3}{*}{6} & $\mathrm{~V}_{1}$ (Beta 1) & $28,28 \mathrm{~g}$ & 40,96 a & $38,32 \mathrm{~d}$ & $29,17 \mathrm{c}$ & 34,18 \\
\hline & $V_{2}$ (Perbaungan) & $35,58 \mathrm{~b}$ & $36,87 \mathrm{f}$ & $31,24 \mathrm{~d}$ & $27,49 \mathrm{e}$ & 32,80 \\
\hline & Rataan & 31,93 & 38,92 & 34,78 & 28,33 & \\
\hline \multirow[t]{3}{*}{7} & $\mathrm{~V}_{1}($ Beta 1$)$ & $37,91 \mathrm{~g}$ & 49,45 a & $42,97 \mathrm{c}$ & $34,90 \mathrm{f}$ & 41,31 \\
\hline & $V_{2}$ (Perbaungan) & $42,94 \mathrm{c}$ & $44,88 \mathrm{~b}$ & $38,87 \mathrm{~d}$ & $38,30 \mathrm{e}$ & 41,25 \\
\hline & Rataan & 40,43 & 47,17 & 40,92 & 36,60 & \\
\hline \multirow[t]{3}{*}{8} & $\mathrm{~V}_{1}$ (Beta 1) & $44,85 \mathrm{f}$ & 54,78 a & $48,30 \mathrm{c}$ & $40,24 \mathrm{~g}$ & 47,04 \\
\hline & $\mathrm{V}_{2}$ (Perbaungan) & $46,86 \mathrm{~d}$ & $48,55 \mathrm{~b}$ & $46,06 \mathrm{e}$ & $45,03 \mathrm{f}$ & 46,63 \\
\hline & Rataan & 45,86 & 51,67 & 47,18 & 42,63 & \\
\hline \multirow[t]{3}{*}{9} & $\mathrm{~V}_{1}($ Beta 1) & $49,50 \mathrm{f}$ & $62,73 \mathrm{a}$ & $53,80 \mathrm{c}$ & $47,73 \mathrm{f}$ & 53,44 \\
\hline & $\mathrm{V}_{2}$ (Perbaungan) & $51,55 \mathrm{e}$ & $55,51 \mathrm{~b}$ & $51,91 \mathrm{~d}$ & $53,97 \mathrm{c}$ & 53,24 \\
\hline & Rataan & 50,53 & 59,12 & 52,86 & 50,85 & \\
\hline \multirow[t]{3}{*}{10} & $\mathrm{~V}_{1}$ (Beta 1) & $53,10 \mathrm{~g}$ & 67,17 a & $58,81 \mathrm{c}$ & $53,30 \mathrm{~g}$ & 58,10 \\
\hline & $\mathrm{V}_{2}$ (Perbaungan) & $55,54 \mathrm{f}$ & $60,71 \mathrm{~b}$ & $57,73 \mathrm{~d}$ & $55,90 \mathrm{e}$ & 57,47 \\
\hline & Rataan & 54,32 & 63,94 & 58,27 & 54,60 & \\
\hline
\end{tabular}

Berdasarkan hasil pengamatan dari sidik ragam diketahui bahwa perlakuan varietas berpengaruh nyata terhadap parameter pertambahan panjang umbi persampel, jumlah umbi per sampel, bobot biomassa per sampel, rataan bobot umbi per sampel, bobot biomassa tanaman.

Hasil penelitian menunjukkan bahwa kedua varietas yang digunakan, yaitu varietas Beta 1 dan varietas lokal Perbaungan memberikan pengaruh yang nyata terhadap pertambahan panjang tanaman ubi jalar pada 1 sampai 4 MST dan pada 6 MST (Tabel 1.). 


\section{Jumlah Umbi per Sampel}

Hasil uji beda rataan parameter jumlah umbi per sampel (umbi) terhadap dua varietas ubi jalar terhadap pemberian berbagai sumber kalium disajikan pada Tabel 2.

Tabel 2. Jumlah umbi per sampel (umbi) dua varietas ubi jalar terhadap pemberian berbagai sumber kalium

\begin{tabular}{|c|c|c|c|c|c|}
\hline \multirow{2}{*}{$\begin{array}{l}\text { Varietas } \\
\text { (V) }\end{array}$} & \multicolumn{4}{|c|}{ Sumber Kalium (K) } & \multirow[b]{2}{*}{ Rataan } \\
\hline & $\begin{array}{c}\left(\mathrm{K}_{0}\right) \\
\text { Kontrol }\end{array}$ & $\begin{array}{c}\mathrm{K}_{1} \\
(\mathrm{KCl} \\
1,5 \mathrm{~g} / \operatorname{tanaman})\end{array}$ & $\begin{array}{c}\mathrm{K}_{2} \\
\text { (Biochar } \\
500 \mathrm{~g} / \operatorname{tanaman})\end{array}$ & $\begin{array}{c}\mathrm{K}_{3} \\
\text { (TKKS } \\
600 \mathrm{~g} / \text { tanaman) }\end{array}$ & \\
\hline$V_{1}($ Beta 1) & $3,17 \mathrm{c}$ & $4,92 \mathrm{a}$ & $4,08 \mathrm{~b}$ & $3,42 \mathrm{c}$ & 3,90 \\
\hline $\mathrm{V}_{2}$ (Perbaungan) & $2,25 \mathrm{de}$ & $2,33 \mathrm{de}$ & $2,58 \mathrm{~d}$ & $2,08 \mathrm{e}$ & 2,31 \\
\hline Rataan & 2,71 & 3,63 & 3,33 & 2,75 & \\
\hline & ( & Olob bo & eda & $\operatorname{kan} b$ & \\
\hline
\end{tabular}
penggunaan dua varietas ubi jalar dan pemberian berbagai sumber kalium serta interaksi kedua perlakuan tersebut berpengaruh nyata terhadap jumlah umbi per sampel, dimana jumlah umbi terbanyak terdapat pada perlakuan varietas Beta 1 dengan $\mathrm{KCl}$ (V1K1), yaitu 4,92 umbi yang berbeda nyata dengan keseluruan perlakuan. Sedangkan jumlah umbi paling sedikit terdapat pada varietas lokal perbaungan dengan TKKS (V2K3), yaitu sebesar 2,08 umbi.

\section{Panjang Umbi per Sampel}

Hasil uji beda rataan parameter panjang umbi per sampel pada dua varietas ubi jalar terhadap pemberian berbagai sumber kalium disajikan pada Tabel 3.

Tabel 3. Panjang umbi per sampel dua varietas ubi jalar terhadap pemberian berbagai sumber kalium

\begin{tabular}{|c|c|c|c|c|c|}
\hline \multirow[b]{2}{*}{$\begin{array}{c}\text { Varietas } \\
\text { (V) }\end{array}$} & \multicolumn{5}{|c|}{ Sumber Kalium (K) } \\
\hline & $\begin{array}{c}\left(\mathrm{K}_{0}\right) \\
\text { Kontrol }\end{array}$ & $\begin{array}{c}\mathrm{K}_{1} \\
(\mathrm{KCl} \\
1,5 \mathrm{~g} / \operatorname{tanaman})\end{array}$ & $\begin{array}{c}\mathrm{K}_{2} \\
\text { (Biochar } \\
500 \mathrm{~g} / \text { tanaman) }\end{array}$ & $\begin{array}{c}\mathrm{K}_{3} \\
\text { (TKKS } \\
600 \mathrm{~g} / \operatorname{tanaman})\end{array}$ & Rataan \\
\hline $\mathrm{V}_{1}$ (Beta 1) & $12,03 \mathrm{e}$ & $13,12 b$ & $13,82 \mathrm{a}$ & $12,86 \mathrm{c}$ & 12,96 \\
\hline $\mathrm{V}_{2}$ (Perbaungan) & $12,79 \mathrm{c}$ & $13,68 \mathrm{a}$ & $11,10 \mathrm{f}$ & $12,49 \mathrm{~d}$ & 12,52 \\
\hline Rataan & 12,41 & 13,40 & 12,46 & 12,67 & \\
\hline
\end{tabular}

Tabel 3 memperlihatkan bahwa penggunaan dua varietas ubi jalar dan pemberian berbagai sumber kalium serta interaksi kedua perlakuan tersebut berpengaruh nyata terhadap panjang umbi per sampel, dimana umbi terpanjang terdapat pada varietas Beta 1 dengan pemberian biochar sekam padi (V1K2), yaitu $13,82 \mathrm{~cm}$ yang berbeda tidak nyata dengan V2K1, namun berbeda nyata dengan semua perlakuan lainnya. Sedangkan panjang umbi terpendek terdapat 
pada perlakuan varietas lokal Perbaungan dengan pemberian biochar sekam padi (V2K2), yaitu $11,10 \mathrm{~cm}$ yang berbeda nyata dengan semua perlakuan lainnya.

\section{Bobot Umbi per Sampel}

Hasil uji beda rataan bobot umbi per sampel (g) terhadap dua varietas ubi jalar terhadap pemberian berbagai sumber kalium disajikan pada Tabel 4.

Tabel 4. Bobot umbi per sampel dua varietas ubi jalar terhadap pemberian berbagai sumber kalium

\begin{tabular}{cccccc}
\hline \multirow{2}{*}{$\begin{array}{c}\text { Varietas } \\
(\mathrm{V})\end{array}$} & \begin{tabular}{c}
$\left.\mathrm{K} \mathrm{K}_{0}\right)$ \\
\cline { 2 - 5 }
\end{tabular} & $\begin{array}{c}\mathrm{K}_{1} \\
(\mathrm{KCl}\end{array}$ & $\begin{array}{c}\mathrm{K}_{2} \\
(\text { Biochar }\end{array}$ & $\begin{array}{c}\mathrm{K}_{3} \\
(\mathrm{TKKS}\end{array}$ & \multirow{2}{*}{ Rataan } \\
& & $1,5 \mathrm{~g} / \operatorname{tanaman})$ & $500 \mathrm{~g} / \operatorname{tanaman})$ & $600 \mathrm{~g} / \operatorname{tanaman})$ & \\
\hline $\mathrm{V}_{1}$ (Beta 1) & $549,17 \mathrm{~cd}$ & $909,17 \mathrm{a}$ & $789,17 \mathrm{~b}$ & $559,17 \mathrm{c}$ & 701,67 \\
$\mathrm{~V}_{2}$ (Perbaungan) & $296,67 \mathrm{e}$ & $500,00 \mathrm{~d}$ & $274,17 \mathrm{e}$ & $315,83 \mathrm{e}$ & 346,67 \\
\hline \multicolumn{1}{c}{ Rataan } & 422,92 & 704,58 & 531,67 & 437,50 & \\
\hline
\end{tabular}

Keterangan : Angka yang diikuti oleh huruf yang berbeda menunjukkan berbeda nyata menurut Uji Jarak Berganda Duncan pada taraf 5\%

Tabel 4 memperlihatkan bahwa penggunaan dua varietas ubi jalar dan pemberian berbagai sumber kalium serta interaksi kedua perlakuan tersebut berpengaruh nyata terhadap bobot umbi per sampel, dimana bobot umbi terbesar terdapat pada varietas Beta 1 dengan pemberian $\mathrm{KCl}$ (V1K1), yaitu 9,09 gram yang berbeda nyata dengan perlakuan lainnya. Sedangkan bobot umbi terkecil terdapat pada perlakuan varietas lokal Perbaungan dengan pemberian biochar sekam padi (V2K2), yaitu 2,74 gram yang tidak berbeda nyata dengan V2K0 dan V2K3, namun berbeda nyata dengan semua perlakuan lainnya.

\section{Rataan Bobot Umbi}

Hasil uji beda rataan parameter rataan bobot umbi terhadap dua varietas ubi jalar terhadap pemberian berbagai sumber kalium disajikan pada Tabel 5.

Tabel 5. Rataan bobot umbi (g) dua varietas ubi jalar terhadap pemberian berbagai sumber kalium

\begin{tabular}{|c|c|c|c|c|c|}
\hline \multirow[b]{2}{*}{ Varietas (V) } & \multicolumn{4}{|c|}{ Sumber Kalium (K) } & \multirow[b]{2}{*}{ Rataan } \\
\hline & $\begin{array}{c}\left(\mathrm{K}_{0}\right) \\
\text { Kontrol }\end{array}$ & $\begin{array}{c}\mathrm{K}_{1} \\
(\mathrm{KCl} \\
1,5 \mathrm{~g} / \operatorname{tanaman}) \\
\end{array}$ & $\begin{array}{c}\mathrm{K}_{2} \\
\text { (Biochar } \\
500 \mathrm{~g} / \text { tanaman) }\end{array}$ & $\begin{array}{c}\mathrm{K}_{3} \\
\text { (TKKS } \\
600 \mathrm{~g} / \operatorname{tanaman})\end{array}$ & \\
\hline $\mathrm{V}_{1}($ Beta 1$)$ & $1,69 \mathrm{def}$ & $1,86 \mathrm{bcd}$ & 2,06 bc & 1,73 bcde & 1,84 \\
\hline $\mathrm{V}_{2}$ (Perbaungan) & $1,36 \mathrm{fg}$ & $2,69 \mathrm{a}$ & $1,12 \mathrm{~g}$ & $1,48 \mathrm{efg}$ & 1,66 \\
\hline Rataan & 1,52 & 2,28 & 1,59 & 1,61 & \\
\hline
\end{tabular}

Keterangan : Angka yang diikuti oleh huruf yang berbeda menunjukkan berbeda nyata menurut Uji Jarak Berganda Duncan pada taraf 5\%

Tabel 5 memperlihatkan bahwa penggunaan dua varietas ubi jalar dan pemberian berbagai sumber kalium serta interaksi kedua perlakuan tersebut berpengaruh nyata terhadap rataan bobot umbi, dimana rataan bobot umbi terbesar terdapat pada varietas lokal perbaungan dengan pemberian $\mathrm{KCl}$ (V2K1), yaitu 2,69 gram yang berbeda nyata dengan perlakuan lainnya. Sedangkan rataan bobot umbi terkecil terdapat pada perlakuan varietas lokal 
Perbaungan dengan pemberian biochar sekam padi (V2K2), yaitu 1,12 gram yang berbeda nyata dengan semua perlakuan lainnya.

\section{Bobot Biomassa Tanaman per Sampel}

Hasil uji beda rataan parameter bobot biomassa tanaman per sampel terhadap dua varietas ubi jalar terhadap pemberian berbagai sumber kalium disajikan pada Tabel 6.

Tabel 6. Bobot biomassa tanaman per sampel (g) dua varietas ubi jalar terhadap pemberian berbagai sumber kalium

\begin{tabular}{|c|c|c|c|c|c|}
\hline \multirow[b]{2}{*}{ Varietas (V) } & \multicolumn{4}{|c|}{ Sumber Kalium (K) } & \multirow[b]{2}{*}{ Rataan } \\
\hline & $\begin{array}{c}\left(\mathrm{K}_{0}\right) \\
\text { Kontrol }\end{array}$ & $\begin{array}{c}\mathrm{K}_{1} \\
(\mathrm{KCl} \\
1,5 \mathrm{~g} / \operatorname{tanaman}) \\
\end{array}$ & $\begin{array}{c}\mathrm{K}_{2} \\
\text { (Biochar } \\
500 \mathrm{~g} / \text { tanaman) }\end{array}$ & $\begin{array}{c}\mathrm{K}_{3} \\
\text { (TKKS } \\
600 \mathrm{~g} / \operatorname{tanaman}) \\
\end{array}$ & \\
\hline $\mathrm{V}_{1}($ Beta 1$)$ & $5,30 \mathrm{~b}$ & $5,40 \mathrm{ab}$ & $5,50 \mathrm{a}$ & $5,60 \mathrm{a}$ & 5,40 \\
\hline $\mathrm{V}_{2}$ (Perbaungan) & $4,70 \mathrm{c}$ & $4,40 \mathrm{~d}$ & $4,40 \mathrm{~d}$ & $4,70 \mathrm{~cd}$ & 4,50 \\
\hline Rataan & 5,00 & 4,90 & 4,90 & 5,10 & \\
\hline
\end{tabular}

Tabel 6 memperlihatkan bahwa penggunaan dua varietas ubi jalar dan pemberian berbagai sumber kalium serta interaksi kedua perlakuan tersebut berpengaruh nyata terhadap bobot biomassa tanaman per sampel, dimana bobot biomassa tanaman terbesar terdapat pada varietas Beta 1 dengan pemberian TKKS (V1K3), yaitu 5,6 gram yang berbeda tidak nyata dengan V1K2, namun berbeda nyata dengan semua perlakuan lainnya. Sedangkan bobot biomassa tanaman terkecil terdapat pada perlakuan varietas lokal Perbaungan dengan pemberian biochar sekam padi (V2K2), yaitu 4,4 gram yang tidak berbeda nyata dengan V2K1, dan berbeda nyata dengan semua perlakuan lainnya.

\section{Indeks Panen}

Hasil uji beda rataan parameter indeks panen terhadap dua varietas ubi jalar terhadap pemberian berbagai sumber kalium disajikan pada Tabel 7 .

Tabel 7. Data indeks panen dua varietas ubi jalar terhadap pemberian berbagai sumber kalium

\begin{tabular}{cccccr}
\hline \multirow{2}{*}{$\begin{array}{c}\text { Varietas } \\
(\mathrm{V})\end{array}$} & $\begin{array}{c}\left(\mathrm{K}_{0}\right) \\
\text { Kontrol }\end{array}$ & $\begin{array}{c}\mathrm{K}_{1} \\
(\mathrm{KCl} \\
1,5 \mathrm{~g} / \text { tanaman) }\end{array}$ & $\begin{array}{c}\text { Sumber Kalium }(\mathrm{K}) \\
(\text { Biochar } \\
500 \mathrm{~g} / \text { tanaman })\end{array}$ & $\begin{array}{c}\mathrm{K}_{3} \\
(\mathrm{TKKS} \\
600 \mathrm{~g} / \text { tanaman })\end{array}$ & Rataan \\
\hline $\mathrm{V}_{1}$ (Beta 1) & 0,45 & 0,61 & 0,57 & 0,49 & 0,53 \\
$\mathrm{~V}_{2}$ (Perbaungan) & 0,38 & 0,49 & 0,37 & 0,36 & 0,40 \\
\hline Rataan & $0,42 \mathrm{a}$ & $0,55 \mathrm{a}$ & $0,47 \mathrm{a}$ & $0,42 \mathrm{a}$ & \\
\hline
\end{tabular}

Keterangan : Angka yang diikuti oleh huruf yang berbeda pada kolom yang sama menunjukkan berbeda nyata berdasarkan Uji Jarak Berganda Duncan pada taraf 5\%

Tabel 7 memperlihatkan bahwa penggunaan dua varietas ubi jalar dan interaksi tidak berpengaruh nyata terhadap indeks panen, namun berpengaruh nyata terhadap pemberian 
berbagai sumber kalium. Indeks panen tertinggi terdapat pada perlakuan V1K1 yaitu 0,61 dimana tidak berbeda nyata dengan perlakuan lainnya. Sedangkan indeks panen terendah terdapat pada perlakuan V2K3, yaitu 0,36.

Varietas tidak memberikan pengaruh yang nyata, dimana nilai indeks panen yang tertinggi terdapat pada varietas Beta 1 yaitu sebesar 0,53, sedangkan varietas lokal Perbaungan hanya sebesar 0,40 . Hal ini mengindikasikan bahwa varietas ubi jalar yang digunakan tidak mampu mendistribusikan asimilat yang banyak ke dalam umbi, sehingga tidak memberikan pengaruh yang nyata terhadap nilai indeks panen tanaman. Hal ini sesuai dengan literatur Suparman (2007) yang menyatakan bahwa indeks panen menunjukkan distribusi bahan kering dalam tanaman yang menunjukkan perimbangan bobot bahan kering yang bernilai ekonomis dengan total bobot kering tanaman pada saat panen.

Kalium dalam tanaman dapat berperan dalam membantu proses fotosintesis, untuk membentuk senyawa organik baru yang akan ditranslokasikan ke organ tempat penyimpanan dalam hal ini umbi dan sekaligus memperbaiki kualitas umbi tanaman ubi jalar. Hal ini sesuai dengan literatur Sianturi dan Ernita (2014) yang menyatakan bahwa $\mathrm{KCl}$ adalah pupuk buatan yang mengandung Kalium (52\% K20) di mana unsur hara tersebut sangat diperlukan tanaman ubi jalar untuk membantu perkembangan umbi.

Sumber kalium yang paling baik dalam menghasilkan bobot biomassa tanaman per sampel adalah perlakuan tandan kosong kelapa sawit. Hal ini disebabkan kompos TKKS mengandung berbagai unsur hara yang dibutuhkan untuk pertumbuhan tanaman. Keunggulan kompos TKKS yaitu mengandung unsur hara yang dibutuhkan tanaman antara lain K, P, Ca, Mg, C dan N. Hal ini sesuai dengan literatur Eleni (2014) yang menyatakan bahwa kompos TKKS memiliki beberapa sifat yang menguntungkan antara lain membantu kelarutan unsur hara yang diperlukan bagi pertumbuhan tanaman.

\section{Simpulan}

Kedua varietas ubi jalar berbeda nyata pada parameter pertambahan panjang tanaman 1 sampai 4 MST dan pada 6 MST, jumlah umbi per sampel, panjang umbi per sampel, bobot umbi per sampel, rataan bobot umbi, dan bobot biomassa tanaman per sampel, dimana hasil tertinggi diperoleh pada varietas Beta 1.

Perlakuan berbagai sumber kalium berpengaruh nyata terhadap semua parameter penelitian. Pertambahan panjang tanaman, jumlah umbi per sampel, panjang umbi per sampel, bobot umbi per sampel, rataan bobot umbi, bobot biomassa tanaman per sampel, dan indeks panen tertinggi dihasilkan pada perlakuan $\mathrm{KCl}$. 3 .

Interaksi perlakuan berbagai sumber kalium terhadap dua varietas ubi jalar berpengaruh nyata pada semua parameter, kecuali pada parameter indeks panen, dimana hasil tertinggi pada parameter pertambahan panjang tanaman, jumlah umbi dan bobot umbi per sampel terdapat pada perlakuan varietas Beta 1 dengan $\mathrm{KCl}$. Parameter panjang umbi per sampel dan rataan bobot biomassa tanaman per sampel tertinggi terdapat pada perlakuan varietas Beta 1 dengan biochar sekam padi. Bobot biomassa per sampel tertinggi terdapat pada perlakuan varietas Beta 1 dengan kompos TKKS. 


\section{Referensi}

Balai Penelitian Tanaman Kacang-Kacangan dan Umbi-Umbian. 2011. Direktorat Jendral Tanaman Pangan. Malang.

Balai Penelitian Tanaman Kacang-Kacangan dan Umbi-Umbian. 2012. Ubi Jalar Varietas Antin-1.Direktorat Jendral Tanaman Pangan. Malang.

Dinas Pertanian Tanaman Pangan. 2012. Petunjuk Teknis Pengolahan Produksi Ubi Jalar. Provinsi Jawa Barat.

Eleni, W. 2014.Pengaruh Kompos Tandan Kosong Kelapa Sawit PadaPertumbuhan Dan Hasil Kacang Tanah. Program Studi Agroteknologi Fak. Pertanian Universitas Tamansiswa. Padang.

Saleh, N. 2011.Peningkatan Produksi Dan Kualitas Umbi-Umbian. Balitkabi. Malang.

Sianturi, D.A dan Ernita. 2014. Penggunaan Pupuk KCl Dan Bokashi Pada TanamanUbi Jalar (Ipomea batatas). Jurnal Dinamika Pertanian Volume XXIX Nomor 1 April 2014 (37 - 44).

Sudjana, B. 2014. Pengaruh Biochar Dan NPK Majemuk Terhadap Biomas Dan Serapan Nitrogen Di Daun Tanaman Jagung (Zea mays) Pada Tanah Typic Dystrudepts. Jurnal Ilmu Pertanian dan Perikanan Juni 2014 Vol. 3 No.1 Hal : 63-66.

Suparman. 2007. Bercocok Tanam Ubi Jalar. Azka Press. Bandung. 